\title{
Topical anesthesia versus peribulbar anesthesia in phacoemulsification cataract surgery and intraocular lens implantation
}

Incaf Elboukhani ${ }^{1 *}$ Choaib Essadouni ${ }^{1}$, Adil Mchachi ${ }^{1}$ Leila Benhmidoune ${ }^{1}$ Abderrahim Chakib $^{1}$, Rayad Rachid ${ }^{1}$, Mohamed Elbelhadji ${ }^{1}$

${ }^{1}$ DEPARTMENT OF ADULT OPHTHALMOLOGY, HOSPITAL AUGUST 20, 1953; CHU IBN ROCHD; HASSAN II UNIVERSITY OF CASABLANCA; MOROCCO

\section{ABSTRACT}

Topical anesthesia during phacoemulsification cataract surgery has become the best choice for ophthalmologists, which broadens the indications for surgery, and eliminates the risk of peribulbar injections. The aim of our study is to assess the advantages and disadvantages, the efficacy and the tolerance of this protocol. Prospective study extending from January 2018 to December 2019, including 116 patients operated for cataracts under topical anesthesia (group 1), and 179 patients under peribulbar anesthesia (group 2). All patients were operated by phacoemulsification. The patients evaluated their pain on a visual analog scale graduated from 1 to 10 . The two groups were comparable in age, gender and history of high blood pressure. All patients received premedication before surgery (Atarax). It was the first eye operated for cataracts in 79 patients in group 1 and 75 patients in group 2. The two groups did not differ significantly in systolic blood pressure rate $(\mathrm{p}=0,36)$, pain score $(\mathrm{p}=0.54)$, duration of surgery $(\mathrm{p}=0.52)$, anaesthesiarelated intraoperative difficulties $(p=0.17)$, or intraoperative surgical complication rate $(\mathrm{p}=0.49)$ or blood oxygen saturation $(\mathrm{p}=0.74)$. However, in the peribulbar groups, better patient and surgeon satisfaction scores were obtained $(\mathrm{P}<.005)$.
Category: Original Research Paper

Received: June 9, 2020

Accepted: August 19, 2020

Keywords:

topical anesthesia, peribulbar anesthesia, phacoemulsification cataract surgery, intraocular lens implantation

*Corresponding author:

Incaf Elboukhani,

Department; Hospital AUGUST 20, 1953; CHU Ibn rochd; Hassan II University of Casablanca; Morocco

E-mail: elboukhaniinsaf@gmail.com

\section{Introduction}

An ideal anesthetic protocol should allow surgery without pain, or systemic or local complications. It should facilitate the procedure for the surgeon and the patient and should be cost effective.

Topical anesthesia during phacoemulsification cataract surgery has become the best choice for ophthalmologists, which broadens the indications for surgery, and eliminates the risk of peribulbar injections.

The aim of our study is to assess the advantages and disadvantages, the efficacy and the tolerance of this protocol in phacoemulsification cataract surgery, as well as patient / surgeon satisfaction.

\section{Materials and Methods}

Prospective study extending from January 2018 to December 2019, including 116 patients operated for cataracts under topical anesthesia (group 1), and 179 patients under peribulbar anesthesia (group 2). All patients were operated by phacoemulsification. The patients evaluated their pain on a visual analog scale graduated from 1 to 10 .

For each patient, we have noted: pain requiring additional anesthesia, hypertensive flare or low blood pressure, respiratory disorder and/ or heart rate, nausea or vomiting, patient agitation. The surgeon reported his intraoperative observations (complications, positive pressure from the vitreous, etc.).

\section{Results}

The two groups were comparable in age, gender and history of high blood pressure (Table I). All patients received premedication before surgery. It was the first eye operated for cataracts in 79 patients in group 1 and 75 patients in group 2. An increase in systolic blood pressure 
greater than $170 \mathrm{mmHg}$ was observed in 23 patients $(15.7 \%)$ in the topical anesthesia group, and in 24 patients $(20 \%)$ in the peribulbar anesthesia group $(\mathrm{p}=0,36)$.

Table I. Characteristics of the population studied

\begin{tabular}{|l|l|l|}
\hline & Group 1 & Group 2 \\
\hline Middle age & 67 & 63 \\
\hline Gender F / M ratio & 1,34 & 1,59 \\
\hline Medical history & & \\
\hline HTA & $74 \%$ & $65,3 \%$ \\
\hline Diabetes & $30 \%$ & $38 \%$ \\
\hline 1st cataract operated & 79 patients & 75 patients \\
\hline 2nd eye & 37 patients & 104 patients \\
\hline
\end{tabular}

During the anesthesia, none of the patients in group 1 complained of pain, $91 \%$ had pain during needle insertion in group 2, intraoperative pain was evaluated on average at $1 / 10$ for group 2 and $2 / 10$ on a VAS for group $1(\mathrm{p}=0.54)$ (Table II).

Table II. Analysis of feelings according to the group

\begin{tabular}{|l|l|l|}
\hline & Group 1 & Group 2 \\
\hline $\begin{array}{l}\text { Average gesture } \\
\text { duration (min) }\end{array}$ & $\begin{array}{c}20 \mathrm{~min} \\
{[11-40 \mathrm{~min}]}\end{array}$ & $\begin{array}{c}15 \mathrm{~min} \\
{[10-45 \mathrm{~min}]}\end{array}$ \\
\hline $\begin{array}{l}\text { Intraoperative pain } \\
\text { EVA }\end{array}$ & $2 / 10$ & $1 / 10$ \\
\hline $\begin{array}{l}\text { Patient satisfaction } \\
\text { EVA }\end{array}$ & $8,86 / 10$ & $8,1 / 10$ \\
\hline $\begin{array}{l}\text { Surgeon satisfaction } \\
\text { EVA }\end{array}$ & $8,49 / 10$ & $8,81 / 10$ \\
\hline
\end{tabular}

EVA: Analog visual scale

The stage most often involved in the genesis of pain was when the conjunctiva was pinched to stabilize the globe to make the service door. In 7 case it was managed by the anesthesiologist, in 8 cases by the surgeon. The immediate postoperative pain on leaving the operating room was on average $2 / 10$. The mean pain at the end of the service or at the withdrawal of the infusion was $1 / 10,4$ patients in group 1 received an additional anesthesia. Positive vitreous pressure was observed in 2 eyes in the topical anesthesia group and in 3 eyes in the peribulbar anesthesia group. Only one of these patients developed a rise in blood pressure at the same time. 3 capsular ruptures occurred in the topical anesthesia group 1 and 4 in group 2 (Table III). The average duration of the operative gesture was approximately 20 minutes, for an interval of 10 to 60 minutes $(\mathrm{p}=0.52) .106$ patients in group 1 said they wanted to be operated on the second eye under the same anesthetic conditions (92.1\%). The surgeon's satisfaction was 8.9 / 10 . In the 24 hours following surgery, in group 1, 95.1\% of the patients experienced no pain. In group 2, $12 \%$ had mild discomfort $(\mathrm{P}<.005)$.

Table III. Intercurrent events

\begin{tabular}{|c|c|c|c|c|c|}
\hline Group & & $\mathbf{n}$ & $\begin{array}{l}\text { Management by } \\
\text { anesthesiologist }\end{array}$ & $\begin{array}{l}\text { Management } \\
\text { by surgeon }\end{array}$ & $\begin{array}{c}\text { No } \\
\text { processing }\end{array}$ \\
\hline \multirow[t]{5}{*}{1} & Pain & 15 & 3 & 12 & - \\
\hline & HTA & 23 & 23 & - & - \\
\hline & Agitation & 3 & 1 & - & 2 \\
\hline & Nausea & 1 & - & - & 1 \\
\hline & $\begin{array}{l}\text { Capsular } \\
\text { ruptures }\end{array}$ & 3 & - & - & - \\
\hline \multirow[t]{5}{*}{2} & Pain & 12 & 7 & 5 & - \\
\hline & HTA & 39 & 39 & - & - \\
\hline & Agitation & 1 & - & - & 1 \\
\hline & Nausea & 2 & - & - & 2 \\
\hline & $\begin{array}{c}\text { Capsular } \\
\text { ruptures }\end{array}$ & 4 & - & - & - \\
\hline
\end{tabular}

\section{Discussions}

The two groups did not differ significantly in systolic blood pressure rate $(\mathrm{p}=0,36)$, pain score $(\mathrm{p}=0.54)$, duration of surgery $(\mathrm{p}=0.52)$, anaesthesia-related intraoperative difficulties $\quad(p=0.17)$ or intraoperative surgical complication rate $(\mathrm{p}=0.49)$ or blood oxygen saturation ( $\mathrm{p}=0.74)$. However, in the peribulbar groups, better patient and surgeon satisfaction scores were obtained $(\mathrm{P}<.005)$.

Topical anesthesia is local anesthesia limited to an analgesic effect. The product is either $0.5 \%$ or $1 \%$ tetracaine or $0.40 \%$ oxybupracaine. The frequency of instillations determines the extent of cell damage. However, proparacaine is the best tolerated solution. This protocol allows the eviction of all complications related to peribulbar anesthesia and seems to provide sufficient anesthetic efficiency, and excellent tolerance [1, 2].

Topical anesthetics blocking the formation and conduction of a nerve impulse from the superficial cornea and the conjunctiva and therefore prevent the central nervous system from receiving a painful stimulus. They act on the cell membrane of neurons blocking the transient sodium permeability that occurs during conduction, axonal depolarization being dependent on sodium transport to the intracellular medium by voltage-sensitive channels [3].

A study carried out to evaluate corneal anesthesia after a single instillation of OXYBUPROCAIN HYDROCHLORIDE $0.4 \%$ in healthy cats has shown that 
long corneal anesthesia was observed 1 minute after the instillation of the eye drops, right eye in all cats. The duration of the maximum corneal anesthesia varied according to the cats from 5 to 30 minutes. It averaged $21.39 \pm 1.71$ minutes for all eyes treated [4].

Pain during peribulbar anesthesia was higher compared to topical anesthetic and was the main reason for the patients' negative reactions.

Numerous studies have evaluated the frequency of intercurrent events during topical subanesthesia cataract surgery, intraoperative pain after topical anesthesia is one of the most frequently reported intercurrent events. In our study the data are comparable, with fairly frequent mild pain, but cases requiring the administration of an intravenous analgesic remained rare, as well as the use of additional anesthesia, performed each time by the surgeon [5-7].

Several authors have compared the two topical and peribulbar techniques in cataract surgery and have reported no significant difference in terms of pain, surgical complications and postoperative visual consequences between these two groups, which was consistent with the results of this study. Only when the topical operation lasted more than almost 30 minutes, this resulted in reduced satisfaction, increased pain and hemodynamic changes $[8,9]$.

In short uncomplicated cataract surgeries, topical anesthesia may still be the preferred method, due to its noninvasive nature, appropriate analgesia, patient satisfaction and stability.

\section{What is already know on this topic}

$\checkmark$ An ideal anesthetic protocol should allow surgery without pain, or systemic or local complications.

$\checkmark$ Topical anesthesia during phacoemulsification cataract surgery is local anesthesia limited to an analgesic effect.

$\checkmark$ Several risks exist in the protocol of peribulbar anesthesia.

\section{What this study adds}

$\checkmark$ There is no significant difference in terms of pain, surgical complications and postoperative visual consequences between the two protocols of topical and peribulbar anesthesia during phacoemulsification cataract surgery

$\checkmark$ The use of simple isolated topical anesthesia for outpatient cataract surgery is legitimate and lawful.

\section{Conclusions}

The use of simple isolated topical anesthesia for outpatient cataract surgery is legitimate and lawful.
Improvements could be envisaged in particular by developing protocols for the management of intercurrent events during surgery and by further strengthening patient information.

\section{Conflict of interest disclosure}

There are no known conflicts of interest in the publication of this article. All authors participated to this study. The manuscript was read and approved by all authors.

\section{Compliance with ethical standards}

Any aspect of the work covered in this manuscript has been conducted with the ethical approval of all relevant bodies and that such approvals are acknowledged within the manuscript.

\section{References}

1. Gombos K, Jakubovits E, Kolos A, Salacz G, Németh J. Cataract surgery anaesthesia: is topical anaesthesia really better than retrobulbar?. Acta Ophthalmol Scand. 2007; 85(3): 309-316. doi:10.1111/j.16000420.2007.00924.x

2. Fung D, Cohen MM, Stewart S, Davies A. What determines patient satisfaction with cataract care under topical local anesthesia and monitored sedation in a community hospital setting?. Anesth Analg. 2005; 100(6):1644-1650. doi:10.1213/01.ANE.0000154206.81132.B9

3. Parkar T, Gogate P, Deshpande M, Adenwala A, Maske A, Verappa K. Comparison of subtenon anaesthesia with peribulbar anaesthesia for manual small incision cataract surgery. Indian J Ophthalmol. 2005;53(4):255259. doi:10.4103/0301-4738.18907

4. Dreno C, Gicquel T, Harry M, et al. Formulation and stability study of a pediatric $2 \%$ phenylephrine hydrochloride eye drop solution. Ann Pharm Fr. 2015;73(1):31-36. doi:10.1016/j.pharma.2014.06.006

5. Dole K, Kulkarni S, Shisode KD, et al. Comparison of clinical outcomes, patient, and surgeon satisfaction following topical versus peribulbar anesthesia for phacoemulsification and intraocular lens implantation: a randomized, controlled trial. Indian J Ophthalmol. 2014;62(9):927-930. doi:10.4103/0301-4738.143929

6. Boezaart A, Berry R, Nell M. Topical anesthesia versus retrobulbar block for cataract surgery: the patients' perspective. J Clin Anesth. 2000;12(1):58-60. doi: 10.1016/s0952-8180(00)00117-3

7. Zhao LQ, Zhu H, Zhao PQ, Wu QR, Hu YQ. Topical anesthesia versus regional anesthesia for cataract surgery: a meta-analysis of randomized controlled 
trials. Ophthalmology. 2012;119(4):659-667. doi: 10.1016/j.ophtha.2011.09.056

8. Pablo LE, Ferreras A, Pérez-Oliván S, Polo V, Honrubia FM. Comparison of the efficacy and safety of contact versus peribulbar anaesthesia in combined eye surgery. Ophthalmologica. 2009;223(1):60-67. doi: $10.1159 / 000173713$
9. Aydin ON, Kir E, Ozkan SB, Gürsoy F. Patientcontrolled analgesia and sedation with fentanyl in phacoemulsification under topical anesthesia. $J$ Cataract Refract Surg. 2002;28(11):1968-1972. doi: 10.1016/s0886-3350(02)01429-3 